\title{
Traffic Analysis of Quality of Service (QoS) for Video Conferencing between Main Campus and Sub Campus in Laboratory Scale
}

\author{
Amang Sudarsono, Anang Siswanto, Heru Iswanto and Qoirul Setiawan \\ Dept. of Electrical Engineering, Division of Telecommunication Engineering, \\ Electronics Engineering Polytechnic Institute of Surabaya (EEPIS), \\ Jalan Raya ITS, Kampus ITS Sukolilo Surabaya 60111, Indonesia \\ amang@pens.ac.id, \{anang,heru\}@staff.pens.ac.id, choirulsetiawan@gmail.com
}

\begin{abstract}
Recently, in the distance learning system, video conferencing becomes one of expected course material delivery systems for creating a virtual class such that lecturer and student which are separated at long distance can engage a learning activity as well as face to face learning system. For this reason, the service availability and quality should be able to guaranteed and fulfilled. In this research, we analyze QoS of video conferencing between main campus and sub campus as the implementation of distance learning system in laboratory scale. Our experimental results show that the channel capacity or bandwidth of WAN connection between main campus and sub campus at $128 \mathrm{kbps}$ is able to generate the throughput of video transmission and reception at $281 \mathrm{kbps}$ and 24 kbps, respectively. Meanwhile, throughput of audio transmission and reception is $64 \mathrm{kbps}$ and $26 \mathrm{kbps}$ with the number of total packet loss for video and audio transmission is $84.3 \%$ and $29.2 \%$, respectively. In this setting, the total jitter for video and audio transmission is 125 $\mathrm{ms}$ and $21 \mathrm{~ms}$, respectively. In this case, there is no packet loss for traffic transmitting and receiving with jitter is not more than $5 \mathrm{~ms}$. We also implemented QoS using Trust CoS model dan Trust DSCP for improving the quality of service in term of jitter up to $12.3 \%$ and $22.41 \%$, respectively.
\end{abstract}

Keywords: quality of service, throughput, delay, jitter, packet loss, Trust CoS, Trust DSCP

\section{INTRODUCTION}

Based on Agosti et. al. [1], distance learning system can be defined as a learning system or process whereas the instructor and student are separated at long distance. By enabling information and communication technology (ICT), course materials can be distributed to the student properly. The used 
of ICT involves network infrastructure such as Internet and equipments to deliver and fetch course materials such as personal computer and laptop PC.

Video conferencing is one of often applied and important distance learning models. In addition, other models such as e-learning, interactive media, e-library, etc are also famous methods for distributing course materials in the distance learning system. Throughout video conferencing, learning process can be conducted as well as face to face learning system if it is supported by a good ICT. In this case, the long distance location between lecturer and student is no longer problem any more in the distance learning system.

Video conferencing technology based on IP is one of very important things for universities in guaranting and ensuring course material distribution as a good university's service to the student. This mechanism will be very important when it is used for distance learning system. However, the operational of video conferencing in two or more different locations and far away one and another will generate a good result if and only if the availability of network resources is guaranteed with low level of latency/delay, packet loss and jitter. This enables a big challenge in the distance learning system which adopts video conferencing system.

Aditya Arie Nugraha et. al. [2][3][4] developed a concept of improving education quality in the elementary school by using ICT to create a virtual class between lecturer and student instead of face to face learning system. The testbed was implemented in the community of elementary school at Keerom-Papua and Subang, Jawa Barat. Authors also analyzed the QoS based on the configuration of audio/video codecs with respect to codec's bit rate. Analyzation was performed by designing and implementing a virtual class service in the laboratory scale and test bed was realized for the distance learning system in Serang Panjang, Subang Jawa Barat [4]. From the investigation result was obtained that a combination between video bit rate at $512 \mathrm{kbps}$ and audio bit rate at $128 \mathrm{kbps}$ causes network load is only $9.6 \%$ with the network throughput $9 \mathrm{Mbps}$ in the laboratory scale. This experimental was done in the ideal topology using network equipments in the laboratory through audio quality measurement with Perceptual Evaluation of Speech Quality (PESQ).

Slamet Sudiarjo et. al. [5] measured QoS of video streaming traffic through Switch layer 2 in the IP based local area network which connects End-to-End codec between two switches. The experimental result was delay time measuerement for audio and video protocol, jitter for each audio and video traffic and packet loss occurs in the video streaming.

Cassidy D. Smith [10] introduced an implementation of video conferencing through IP based network with QoS configuration both in the core network, distribution network and access network using Cisco equipments to connect End-to-End codec over WAN connection. In addition, Cisco Corp. introduced a solution regarding communication and 
collaboration throughout Cisco Unified Communication [8] and its application for video conferencing [9].

In this research, we use network infrastructure in the Network Administration and Security Laboratory at EEPIS campus. Developing a video conferencing system as a part of Unified Call Manager System [8][9] for real conferencing between main campus and sub campus is our main target. This system is inspired from the concept of video conferencing in the company when they have online meeting between End-point in headquarter office and End-point in the branch office instead of face to face meeting. This mechanism is performed to reduce the cost of business travelling and phone call usage. Comprehensively analysis of video conferencing which consist of all configuration of various audio/video codec with its bit rate and other QoS parameters such as throughput, delay, jitter and packet loss is conducted in this research.

\section{IP BASED VIDEO CONFERENCING TECHNOLOGY}

IP based video conferencing technology is one of very important for universities in guaranting a course materials distribution as an offering service to student. This mechanism will be realized for the appropriate goal such as distance learning system. In this section, we describe the fundamental technology related to this topic of interest.

\subsection{End-to-End Point Quality of Service in Campus Video Conferencing}

Network connects two campuses through WAN connection. Usually, WAN coonection is provided by city network provider such as ISDN/ATM, DSL, SONET, Wireless WAN, Metro Ethernet, and other public connections including Internet. Edge routers forward audio and video traffic from Gatekeeper or WAN and keep the quality of service based on queue priority. Network devices such as Layer 2 Switch maps Class of Service (CoS) value into Differentiated Service (Diffserv) value to network devices Layer 3. In these Layer 3 devices, the route of traffic is determined based on priority. Furthermore, Layer 2 Switch classifies and prioritizes bits of CoS. Network devices used for video conferencing mark the traffic by assigning CoS values or Differentiated Services Code Point (DSCP) values, In this situation, Switch only needs a trust in CoS values of port where the codec connected.

\subsection{QoS Technology}

The important issues in video conferencing are the availability of bandwidth, packet loss, delay and jitter or delay variance. Bandwidth availability means the available data during transmission and it is expressed for deciding channel capacity in megabits per seconds (Mbps). Packet loss denotes a prosentage of failed received data by codec from the transmission process. Delay or latency can be represented by the average time between data transmission and data reception and it is usually expressed by milliseconds (ms). Meanwhile jitter is a latency variance in the part of 
transmission process. Jitter can be measured through various ways such as the different between the highest latency and the lowest latency, standard deviation of latency, etc. On the other word, jitter is always given in qualitative or delay variation of data traffic during transmission process.

QoS technology could be enabled in the Layer 2 and Layer 3 network devices. To guarantee the quality of End-to-End communication, it is required a mapping process from Layer 2 to Layer 3. In this case, QoS values are translated between CoS values in the Layer 2 and DSCP values in the Layer 3. Table 1 shows the example of mapping values from Layer 2 to Layer 3 . There is no standard for priority of various traffic types should be obtained. This is just as a recommendation when working on video conferencing.

Table 1. Mapping CoS values in Layer 2 into DSCP values in Layer 3. [10]

\begin{tabular}{|c|c|c|c|c|}
\hline Type of traffic & $\begin{array}{c}\text { CoS values } \\
\text { in Layer 2 }\end{array}$ & $\begin{array}{c}\text { IP precendence } \\
\text { in Layer 3 }\end{array}$ & \multicolumn{2}{|c|}{$\begin{array}{c}\text { DSCP values } \\
\text { in Layer 3 }\end{array}$} \\
\hline Reserved & 7 & 7 & - & $(56)$ \\
\hline Reserved & 6 & 6 & - & $(48)$ \\
\hline Voice & 5 & 5 & $\mathrm{EF}$ & $(46)$ \\
\hline Video Conference & $\mathbf{4}$ & $\mathbf{4}$ & $\mathrm{AF41}$ & $\mathbf{( 3 4 )}$ \\
\hline Call Control & 3 & 3 & $\mathrm{AF} 31$ & $(26)$ \\
\hline $\begin{array}{c}\text { High Priority } \\
\text { Data/Streaming Video }\end{array}$ & 2 & 2 & $\mathrm{AF} 21$ & $(18)$ \\
\hline Medium Priority Data & 1 & 1 & $\mathrm{AF} 11$ & $(10)$ \\
\hline Best Effort Data & 0 & 0 & $\mathrm{BE}$ & $(0)$ \\
\hline
\end{tabular}

\subsection{Non-QoS Parameter Impact in Video Conferencing}

In addition of above QoS parameters such as throughput, delay, packet loss, and jitter, regarding [10] the following are non-QoS parameters influence quality of service in video conferencing:

- Call Manager Software: this software should be installed in backbone network and edge routers. Ideally, this software should be directly connected to the core switch and it is recommended to have not more than one hop from edge router.

- Ethernet speed and duplexing: it is recommended to configure ethernet connection manually to $100 \mathrm{Mbps}$ and full-duplex. Normally, video transmission requires at least $384 \mathrm{kbps}$ for $10 \mathrm{Mbps}$ half-duplex Ethernet connection to get a good performance. However, full-duplex setting is not enough if there is no matching duplex among network devices. As the result, video conferencing may have a problem. Therefore, it is recommended to use manageable devices such that Ethernet speed and duplex can be configured manually.

- Spanning tree is a mechanism to prevent routing-loop, due to routing-loop affects longer convergence time. By controlling spanning tree, the convergence time of network topology can be achieved as fast as possible. In video conferencing implementation, convergence time is very important to improve the quality of video conferencing. 
- Codec: several codes are not easy to work in high speed and duplex Ethernet ports. Some other else may have a feature to mark incoming packet and perform priority mechanism based on CoS and DSCP values. Higher end codecs usually have both priority mechanism and packet marking features to eliminate packet loss.

- Other equipments such as camera, microphone and speaker that are not working properly cause lower quality of service in video conferencing system.

- Firewall: this feature also introduces delay time. Applying firewall usually used for enabling security feature, but it can be decreased the quality of service. To get the best performance in video conferencing, it is recommended to disable firewall feature.

\section{VIDEO CONFERENCING SYSTEM BETWEEN MAIN CAMPUS AND SUB CAMPUS}

This research explains about quality of service for video conferencing system practically by using network devices in the Network Management and Security Laboratory at EEPIS campus. This section will describe method, network topology, implementation, and quality of service measurement and its investigation.

Video transmission over IP based network is very sensitive from delay and jitter may occur in the network. This situation is very important for campus to ensure and guarantee the quality of video transmission as a good service to the student when such mechanism is used for delivering course materials. This research illustrates network configuration with fulfillment all requirements in implementing quality of service of End-to-End devices involve in the video conferencing system between main campus and sub campus. Main campus network and sub campus network are connected over WAN connection. In this case, quality of service of WAN connection also determines the quality of video transmission in the video conferencing system.

Previous sections have mentioned that the main goal of this research is to develop a Unified Call Manager system to establish a video conferencing service for distance learning system and analyze its quality of service comprehensively with respect to affected factors such that the suitable quality of service can be achieved for a good result of distance learning system.

Topology model of Unified Call Manager System is used for providing video conferencing service in the laboratory scale. In this research, the network topology of the system is described in Figure 1. We use Cisco devices to develop the system infrastructure. 


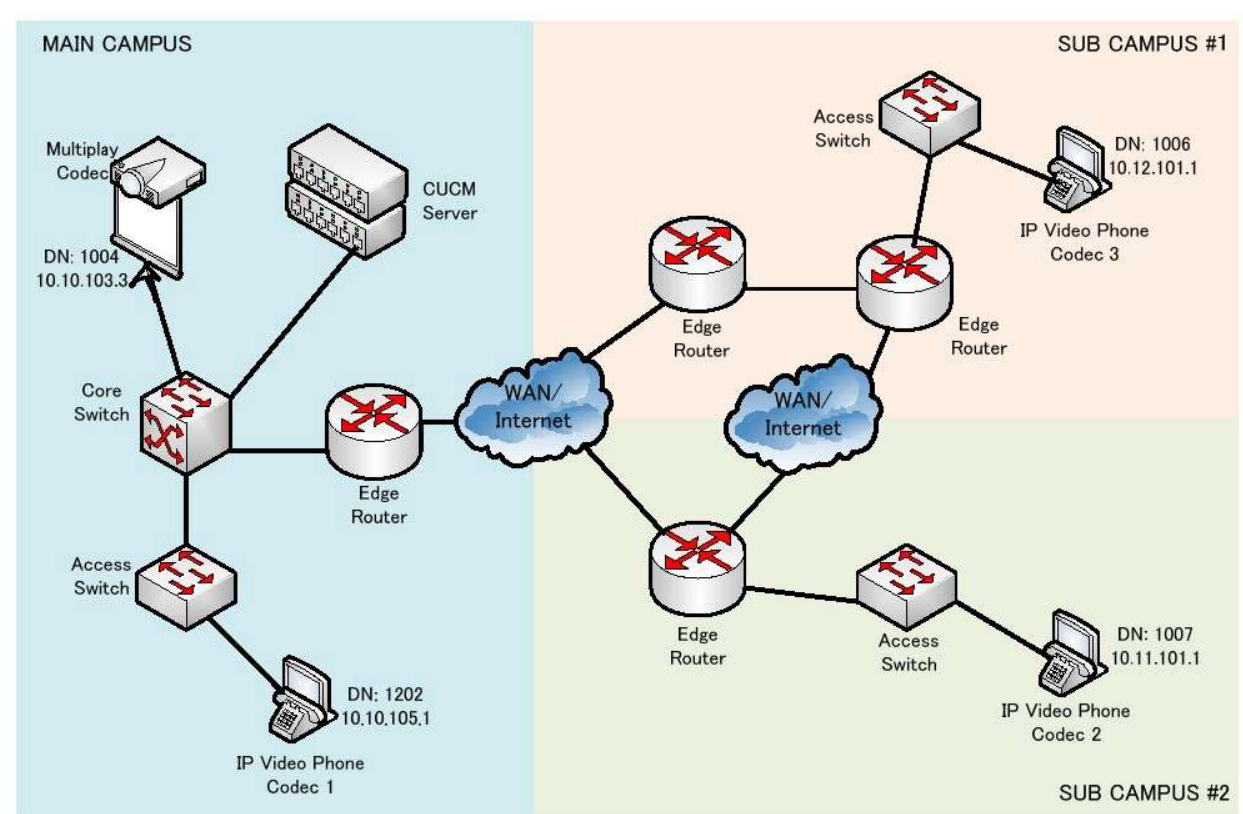

Figure 1. Topology model of video conferencing system between main campus and sub campus in laboratory scale.

In this system model, we collaborate the functions of IP communications, telepresence, conferencing (i.e., including video conferencing), messaging, and mobile applications [8]. Telephony function is handled by equipments such as: (1) Call Manager which has a function as IP PBX system for registration process, dial-plan, voice bandwidth management and voice gateway management; (2) Voice Gateway which has a function as a gateway in the network devices to convert realtime voice call between circuit-switched telephone network and IP network; (3) Endpoint IP Phone which has a function as an End-point of user to perform voice call. In this research, QoS analyzing will be executed based on four issues needed for fulfilling quality of service such as packet delay, jitter, packet loss and throughput.

Cisco Unified Call Manager (CUCM) [8] provides telephony feature and forwarding feature to route telephony packets passthrough network devices. These packets comprise IP phone, media processing device, VoIP gateway, and multimedia applications. Meanwhile, data, voice, and video service such as convergence message, conferencing, collaborative contact center and interactive voice response system (IVR) interact with IP telephony through CUCM application. Based on [8], the functions of CUCM are as follows:

- Call processing means a fuction for originating, routing and call terminating, including billing system.

- Signaling and device control: CUCM sets signaling connection between endpoint call and devices such as gateway and conferencing-bridge to establish streaming connection. This function also is used for calling control and calling setup. 
- Dial plan administration: this function includes setting list of configuration for call routing. CUCM responsibles to analyze digit number for all call and allows user to make dial plan.

- Phone feature administration: this function covers additional features of CUCM such as hold, transfer, forward, conference, speed dial, redial, call park, and other features for IP phone and gateway.

- Directory service: CUCM uses its own database to store user information. User authentication is done locally or using external directory.

- Programming interface to external applications: CUCM provides interface programming to external applications such as IP softphone, IP communicator, Unified IP interactive voice response (IP IVR), personal assistant, unified personal assistant and console.

\section{IMPLEMENTATION OF TRUST CoS and TRUST DSCP}

In this work, we implemented Trust CoS and Trust DSCP on the interfaces of the teleconferencing devices in our video conferencing system between main campus and sub campus as shown in Figure 1.

\subsection{Trust CoS}

Basically, this model is able to improve the quality of service by increasing the performance in the Layer 2 devices such as switches. The algorithm of Trust $\mathrm{CoS}$ is described in Algorithm 1.

Algorithm 1. Trust CoS generation algorithm.

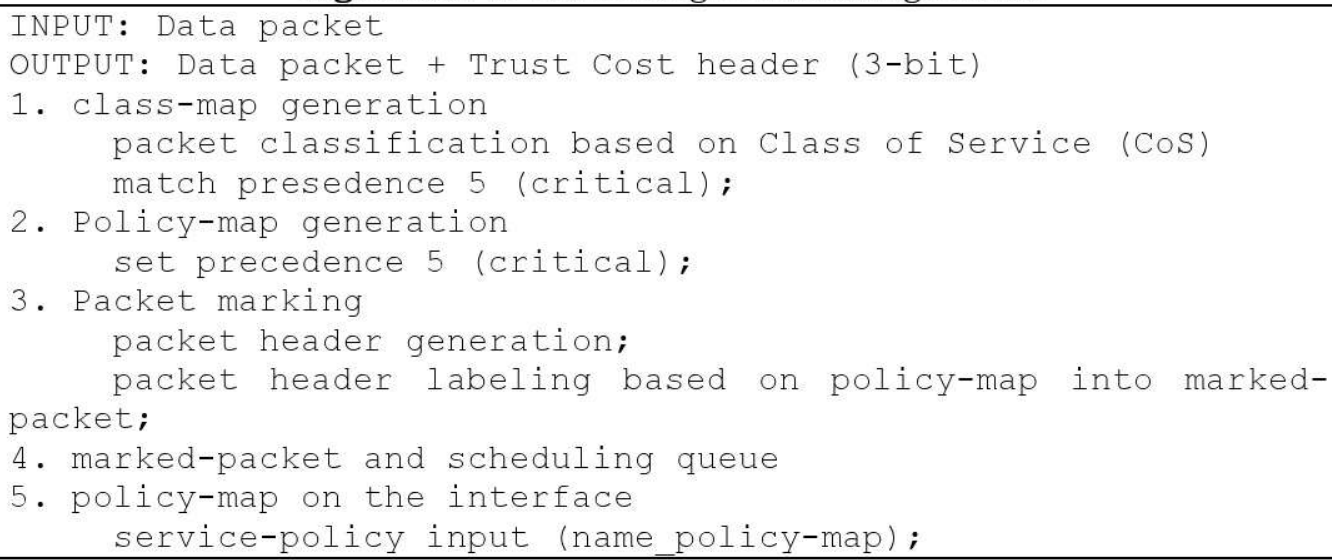

Trust CoS implementation on the devices, especially switches is started by class-map generation which has a function to group the packets based on the class of service type, such as IP address or source port. Then, it generates policy-map to provide the priority of generated class. We set precendence 5 , due to the priority of the packet is critical. After determining the priority of policy, such policy is applied on the interfaces. 


\subsection{Trust DSCP}

Different from Trust CoS, this model is able to improve the quality of service by applying the performance of Layer 2 and Layer 3 devices such as routers. The mechanism of Trust DSCP is described in Algorithm 2.

Algorithm 2. Trust DSCP generation algorithm

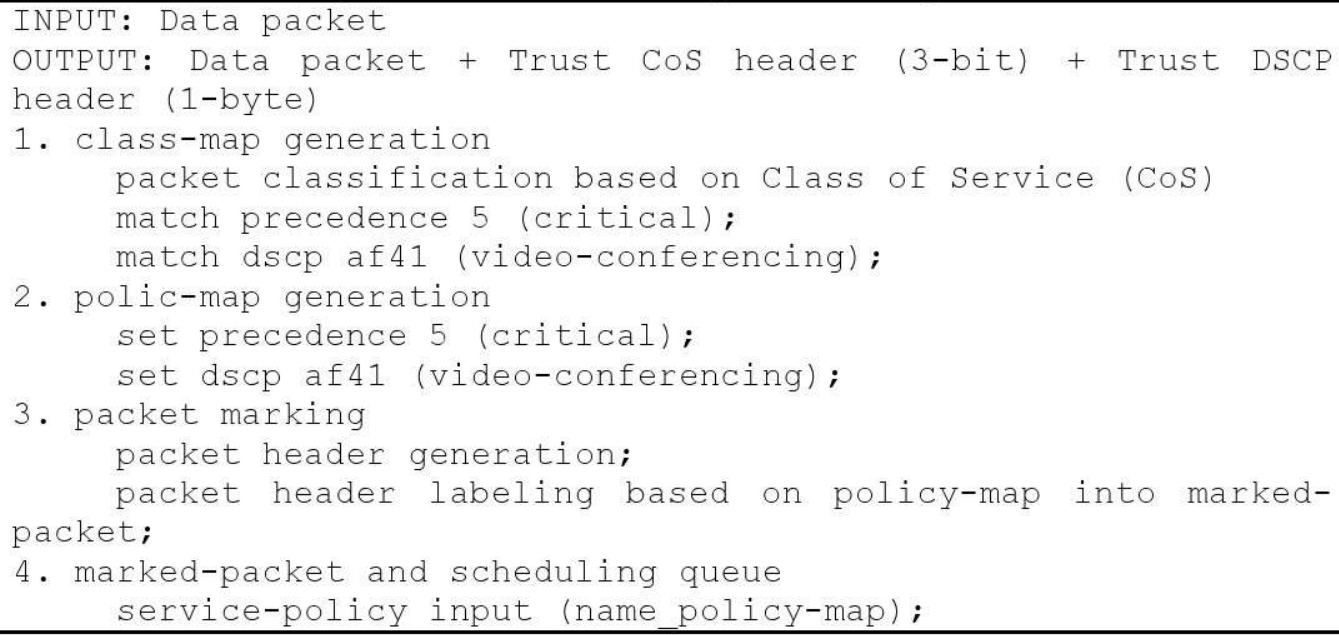

Similar to Trust CoS, Trust DSCP implementation on the devices is started by class-map generation which has a function to group the packets based on Class of Service type such as IP address and source port.

We selected af41 for grouping inbound traffic of video conferencing. Then, policy-map is generated to provide a priority of the class. Set precedence 5 is selected, due to this set is critical. In this priority decision, it is added teleconference packets so that a set of priority is also af41. And finally, the policy is applied on the interfaces.

\section{EXPERIMENTAL RESULTS AND ANALYSIS}

In this section, we describe our experimental results and the analysis of video conferencing performance between End-point in the main campus and End-point in the sub campus. Measurement and analysis comprise the investigation of packet delay, jitter, throughput and packet loss from the quality of audio and video.

\subsection{Network Topology in the Testbed}

Figure 2 illustrates the network topology in our experiments to investigate the quality of video conferencing system for distance learning between codec in main campus and codecs in sub campus \#1 and sub campus \#2. 


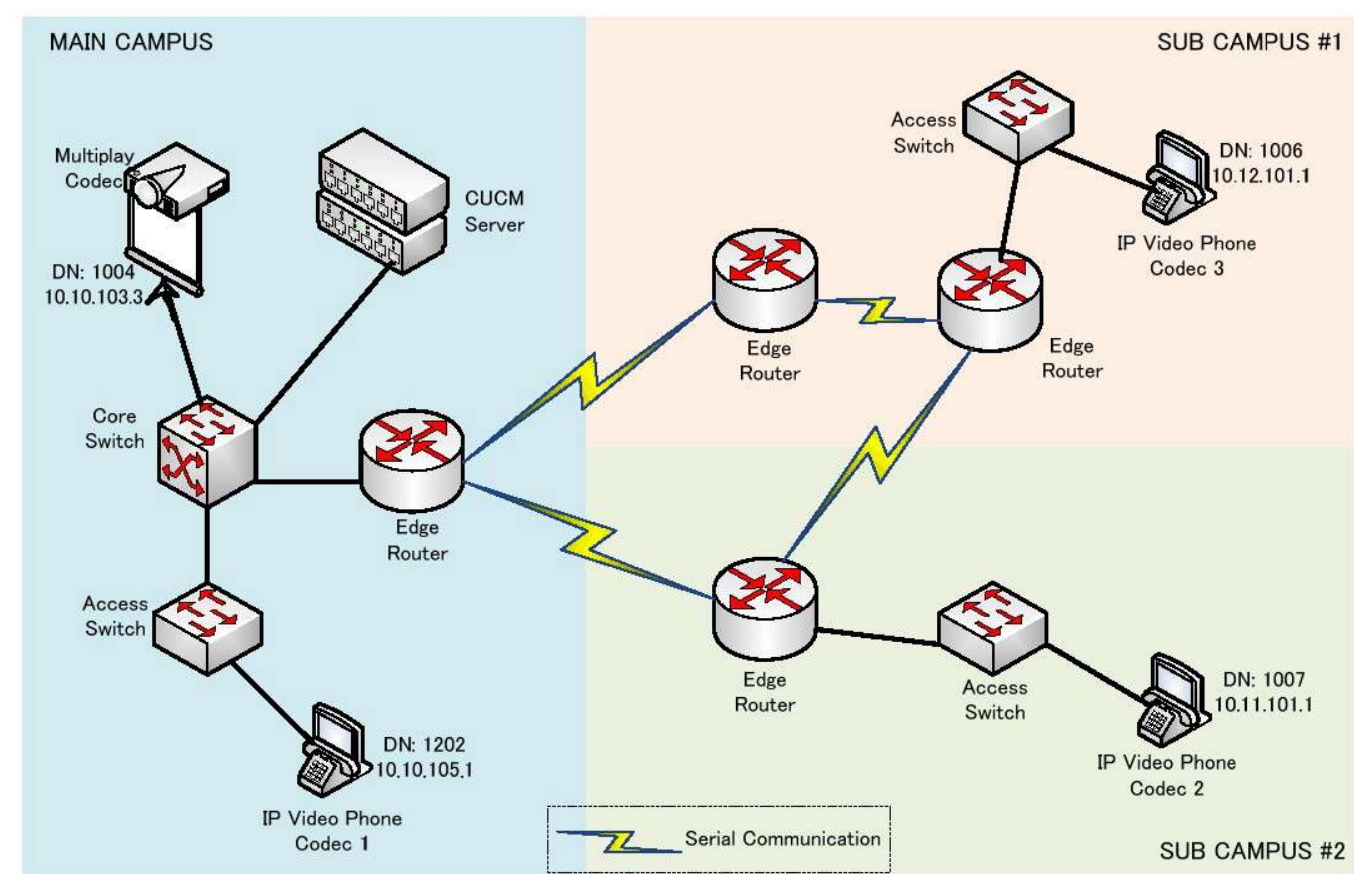

Figure 2. Network topology in the testbed.

We use Cisco EX90 Multiplay codec and IP video phone codec as the End-points in main campus. Cisco EX90 codec has a feature to conduct a room video conferencing with maximum 4 connected codecs simultaneously and it is assigned into a dial number (DN) 1004 with IP address 10.10.103.3. Whilst, IP video phone is set to DN 1202 with IP address 10.10.105.1 over main campus network in Gbps capacity. Meanwhile, End-point codec in sub campus \#1 and sub campus \#2 use IP video phone over sub campus network in Gbps capacity. They are assigned to DN 1006 with IP address 10.12.101.1 in sub campus \#1 and DN 1007 with IP address 10.11.101.1 in sub campus \#2, respectively.

\subsection{Quality of Service Measurement and Analysis}

Measurement is carried out by seting channel capacity of WAN connection $128 \mathrm{kbps}, 512 \mathrm{kbps}, 1 \mathrm{Mbps}$ and $2 \mathrm{Mbps}$. To do so, we operated serial connection to acquire the expected channel capacity instead of WAN connection (see our testbed network topology in Figure 2). We utilized H264 format of video traffic with transmission frame resolution $640 \times 368$ and reception frame resolution $352 \times 288$. Meanwhile, G722-Mono is utilized for audio traffic transmission. Table 2 shows the quality of service measurement for channel capacity of WAN connection $128 \mathrm{kbps}$. This measurement is taken from End-point Multiplay codec. 
Table 2. Quality of service for channel capacity of WAN connection $128 \mathrm{kbps}$.

\begin{tabular}{|c|c|c|c|c|c|c|c|}
\hline \multirow{2}{*}{$\begin{array}{c}\text { Traffic } \\
\text { Type }\end{array}$} & \multirow{2}{*}{$\begin{array}{c}\text { QoS } \\
\text { Parameter }\end{array}$} & \multicolumn{2}{|c|}{ DN: 1006} & \multicolumn{2}{|c|}{ DN: 1007} & \multicolumn{2}{|c|}{ DN: 1202} \\
\hline & & Transmit & Receive & Transmit & Receive & Transmit & Receive \\
\hline \multirow{7}{*}{ Video } & Protocol & H264 & H264 & H264 & H264 & H264 & H264 \\
\hline & Resolution & $640 \times 368$ & $352 \times 288$ & $640 \times 368$ & $352 \times 288$ & $640 \times 368$ & $352 \times 288$ \\
\hline & Frame Rate & 30 & 3 & 30 & 3 & 30 & 30 \\
\hline & Channel Rate & $307 \mathrm{kbps}$ & $21 \mathrm{kbps}$ & $248 \mathrm{kbps}$ & $21 \mathrm{kbps}$ & $49 \mathrm{kbps}$ & $317 \mathrm{kbps}$ \\
\hline & $\begin{array}{l}\text { Total Packet } \\
\text { Loss (\%) }\end{array}$ & $0.0 \%$ & $91.0 \%$ & $0.0 \%$ & $90.0 \%$ & $0.0 \%$ & $0.0 \%$ \\
\hline & $\begin{array}{l}\text { Current } \\
\text { Packet Loss } \\
(\%)\end{array}$ & $0.0 \%$ & $92.5 \%$ & $0.0 \%$ & $93.3 \%$ & $0.0 \%$ & $0.0 \%$ \\
\hline & Jitter & $0 \mathrm{~ms}$ & $143 \mathrm{~ms}$ & $0 \mathrm{~ms}$ & $143 \mathrm{~ms}$ & $0 \mathrm{~ms}$ & $1 \mathrm{~ms}$ \\
\hline \multirow{5}{*}{ Audio } & Protocol & $\begin{array}{l}\text { G722- } \\
\text { Mono }\end{array}$ & $\begin{array}{l}\text { G722- } \\
\text { Mono }\end{array}$ & $\begin{array}{l}\text { G722- } \\
\text { Mono }\end{array}$ & $\begin{array}{l}\text { G722- } \\
\text { Mono }\end{array}$ & $\begin{array}{l}\text { G722- } \\
\text { Mono }\end{array}$ & $\begin{array}{l}\text { G722- } \\
\text { Mono }\end{array}$ \\
\hline & Channel Rate & $64 \mathrm{kbps}$ & $23 \mathrm{kbps}$ & $64 \mathrm{kbps}$ & $23 \mathrm{kbps}$ & $63 \mathrm{kbps}$ & $63 \mathrm{kbps}$ \\
\hline & $\begin{array}{l}\text { Total Packet } \\
\text { Loss }(\%)\end{array}$ & $0.0 \%$ & $62.4 \%$ & $0.0 \%$ & $52.2 \%$ & $0.0 \%$ & $0.0 \%$ \\
\hline & $\begin{array}{l}\text { Current } \\
\text { Packet Loss } \\
(\%)\end{array}$ & $0.0 \%$ & $64.9 \%$ & $0.0 \%$ & $62.3 \%$ & $0.0 \%$ & $0.0 \%$ \\
\hline & Jitter & $0 \mathrm{~ms}$ & $43 \mathrm{~ms}$ & $0 \mathrm{~ms}$ & $28 \mathrm{~ms}$ & $0 \mathrm{~ms}$ & $5 \mathrm{~ms}$ \\
\hline
\end{tabular}

In the setting of $128 \mathrm{kbps}$ WAN connection of video conferencing between End-point in main campus (DN: 1004) and End-points in sub campus \#1 (DN: 1006) and sub campus \#2 (DN: 1007), throughput of video transmission is $307 \mathrm{kbps}$ and $248 \mathrm{kbps}$, respectively, whereas video reception is $21 \mathrm{kbps}$. In this situation, total packet loss of video reception is about $90 \%$ and jitter is $143 \mathrm{~ms}$. On the other hand, the throughput of audio transmission is $64 \mathrm{kbps}$ and $23 \mathrm{kbps}$ for the reception with total packet loss of audio reception is $62 \%$ and $42 \%$., respectively, whereas jitter is $43 \mathrm{~ms}$ and $28 \mathrm{~ms}$, respectively. This shows that quality of service is very bad for channel capacity of WAN connection 128 kbps. Meanwhile, the quality of video conferencing between End-points in main campus (i.e., between DN: 1004 and DN: 1202) which has bandwidth in Gbps orde yields the throughput of video reception $317 \mathrm{kbps}$ with jitter is only $1 \mathrm{~ms}$ and no packet loss, whereas the throughput of audio reception is $64 \mathrm{kbps}$ with jitter is only $5 \mathrm{~ms}$. Furthermore, by applying QoS in the Access Switch in sub campus with Trust CoS model, we can improve the quality of service as shown in Table 3. Again, this quality of service improvement is measured from End-point in main campus (i.e., DN: 1004).

Table 3. Quality of service for channel capacity of WAN connection $128 \mathrm{kbps}$ with QoS.

\begin{tabular}{|l|l|l|l|}
\hline \multirow{2}{*}{ Traffic Type } & \multirow{2}{*}{ QoS Parameter } & \multicolumn{2}{|c|}{ DN: 1007 } \\
\cline { 3 - 4 } & & \multicolumn{1}{|c|}{ Transmit } & \multicolumn{1}{|c|}{ Receive } \\
\hline \multirow{4}{*}{ Video } & Protocol & H264 & H264 \\
\cline { 2 - 4 } & Resolution & $640 \times 368$ & $352 \times 288$ \\
\cline { 2 - 4 } & Frame Rate & 30 & 4 \\
\cline { 2 - 4 } & Channel Rate & $281 \mathrm{kbps}$ & $24 \mathrm{kbps}$ \\
\cline { 2 - 4 } & Total Packet Loss (\%) & $0.0 \%$ & $84.3 \%$ \\
\hline
\end{tabular}




\begin{tabular}{|l|l|l|l|}
\hline \multirow{4}{*}{} & Current Packet Loss (\%) & $0.0 \%$ & $90.9 \%$ \\
\cline { 2 - 4 } & Jitter & $0 \mathrm{~ms}$ & $125 \mathrm{~ms}$ \\
\hline \multirow{4}{*}{ Audio } & Protocol & G722-Mono & G722-Mono \\
\cline { 2 - 4 } & Channel Rate & $64 \mathrm{kbps}$ & $26 \mathrm{kbps}$ \\
\cline { 2 - 4 } & Total Packet Loss (\%) & $0.0 \%$ & $29.2 \%$ \\
\cline { 2 - 4 } & Current Packet Loss (\%) & $0.0 \%$ & $57.2 \%$ \\
\cline { 2 - 4 } & Jitter & $0 \mathrm{~ms}$ & $21 \mathrm{~ms}$ \\
\hline
\end{tabular}

The throughput improvement after applying QoS of video traffic transmission increases $40 \mathrm{kbps}$ and $3 \mathrm{kbps}$ for the reception, respectively with packet loss decreases into $84 \%$ and jitter becomes $125 \mathrm{~ms}$.

Table 4 and Table 5 show the result of quality of service measurement before applying QoS and after applying QoS with Trust CoS model for the channel capacity of WAN connection $512 \mathrm{kbps}$. Theoretically, the minimum standard of channel capacity of WAN connection to conduct a good quality of video conferencing is $384 \mathrm{kbps}$. Our experimental result shows that the throughput of video traffic transmission and reception is $135 \mathrm{kbps}$ and 315 kbps, respectively without packet loss and jitter is only $6 \mathrm{~ms}$ for transmission and $8 \mathrm{~ms}$ for reception. Meanwhile, the throughput of audio traffic transmission and reception is $64 \mathrm{kbps}$ without packet loss and jitter for transmission is $7 \mathrm{~ms}$ and $8 \mathrm{~ms}$ for reception.

Table 4. Quality of service for channel capacity of WAN connection $512 \mathrm{kbps}$.

\begin{tabular}{|c|c|c|c|c|c|c|c|}
\hline \multirow{2}{*}{$\begin{array}{l}\text { Traffic } \\
\text { Type }\end{array}$} & \multirow{2}{*}{ QoS Parameter } & \multicolumn{2}{|c|}{ DN: 1006} & \multicolumn{2}{|c|}{ DN: 1007} & \multicolumn{2}{|c|}{ DN: 1202} \\
\hline & & Transmit & Receive & Transmit & Receive & Transmit & Receive \\
\hline \multirow{7}{*}{ Video } & Protocol & H264 & H264 & H264 & H264 & H264 & H264 \\
\hline & Resolution & $640 \times 368$ & $352 \times 288$ & $640 \times 368$ & $352 \times 288$ & $640 \times 368$ & $352 \times 288$ \\
\hline & Frame Rate & 30 & 30 & 30 & 30 & 30 & 30 \\
\hline & Channel Rate & $\begin{array}{l}135 \\
\text { kbps }\end{array}$ & $312 \mathrm{kbps}$ & $134 \mathrm{kbps}$ & $315 \mathrm{kbps}$ & $155 \mathrm{kbps}$ & $317 \mathrm{kbps}$ \\
\hline & $\begin{array}{l}\text { Total Packet } \\
\text { Loss (\%) }\end{array}$ & $0.0 \%$ & $0.0 \%$ & $0.0 \%$ & $0.0 \%$ & $0.0 \%$ & $0.0 \%$ \\
\hline & $\begin{array}{l}\text { Current Packet } \\
\text { Loss (\%) }\end{array}$ & $0.0 \%$ & $0.0 \%$ & $0.0 \%$ & $0.0 \%$ & $0.0 \%$ & $0.0 \%$ \\
\hline & Jitter & $0 \mathrm{~ms}$ & $6 \mathrm{~ms}$ & $0 \mathrm{~ms}$ & $8 \mathrm{~ms}$ & $0 \mathrm{~ms}$ & $1 \mathrm{~ms}$ \\
\hline \multirow{5}{*}{ Audio } & Protocol & $\begin{array}{l}\text { G722- } \\
\text { Mono }\end{array}$ & $\begin{array}{l}\text { G722- } \\
\text { Mono }\end{array}$ & $\begin{array}{l}\text { G722- } \\
\text { Mono }\end{array}$ & $\begin{array}{l}\text { G722- } \\
\text { Mono }\end{array}$ & $\begin{array}{l}\text { G722- } \\
\text { Mono }\end{array}$ & $\begin{array}{l}\text { G722- } \\
\text { Mono }\end{array}$ \\
\hline & Channel Rate & $64 \mathrm{kbps}$ & $63 \mathrm{kbps}$ & $64 \mathrm{kbps}$ & $64 \mathrm{kbps}$ & $63 \mathrm{kbps}$ & $63 \mathrm{kbps}$ \\
\hline & $\begin{array}{l}\text { Total Packet } \\
\text { Loss }(\%)\end{array}$ & $0.0 \%$ & $0.0 \%$ & $0.0 \%$ & $0.0 \%$ & $0.0 \%$ & $0.0 \%$ \\
\hline & $\begin{array}{l}\text { Current Packet } \\
\text { Loss (\%) }\end{array}$ & $0.0 \%$ & $0.0 \%$ & $0.0 \%$ & $0.0 \%$ & $0.0 \%$ & $0.0 \%$ \\
\hline & Jitter & $0 \mathrm{~ms}$ & $8 \mathrm{~ms}$ & $0 \mathrm{~ms}$ & $7 \mathrm{~ms}$ & $0 \mathrm{~ms}$ & $0 \mathrm{~ms}$ \\
\hline
\end{tabular}

Table 5 shows that applying QoS for channel capacity of WAN connection above $384 \mathrm{kbps}$ (i.e., $512 \mathrm{kbps}$ ) is not significant impact on changes in quality of service for video conferencing. 
Table 5. Quality of service for channel capacity of WAN connection $512 \mathrm{kbps}$ with QoS.

\begin{tabular}{|c|l|l|l|}
\hline Traffic & \multirow{2}{*}{ QoS Parameter } & \multicolumn{2}{|c|}{ DN: 1007 } \\
\cline { 3 - 4 } & & Transmit & Receive \\
\hline \multirow{5}{*}{ Video } & Protocol & $\mathrm{H} 264$ & $\mathrm{H} 264$ \\
\cline { 2 - 4 } & Resolution & $640 \mathrm{x} 368$ & $352 \times 288$ \\
\cline { 2 - 4 } & Frame Rate & 30 & 30 \\
\cline { 2 - 4 } & Channel Rate & $155 \mathrm{kbps}$ & $317 \mathrm{kbps}$ \\
\cline { 2 - 4 } & Total Packet Loss (\%) & $0.0 \%$ & $0.0 \%$ \\
\cline { 2 - 4 } & Current Packet Loss (\%) & $0.0 \%$ & $0.0 \%$ \\
\cline { 2 - 4 } & Jitter & $0 \mathrm{~ms}$ & $8 \mathrm{~ms}$ \\
\hline \multirow{5}{*}{ Audio } & Protocol & $\mathrm{G} 722-\mathrm{Mono}$ & $\mathrm{G} 722-\mathrm{Mono}$ \\
\cline { 2 - 4 } & Channel Rate & $64 \mathrm{kbps}$ & $64 \mathrm{kbps}$ \\
\cline { 2 - 4 } & Total Packet Loss (\%) & $0.0 \%$ & $0.0 \%$ \\
\cline { 2 - 4 } & Current Packet Loss (\%) & $0.0 \%$ & $0.0 \%$ \\
\cline { 2 - 4 } & Jitter & $0 \mathrm{~ms}$ & $7 \mathrm{~ms}$ \\
\hline
\end{tabular}

Table 6 shows the comparison of quality of service for channel capacity of WAN connection $128 \mathrm{kbps}, 512 \mathrm{kbps}, 1 \mathrm{Mbps}$, and $2 \mathrm{Mbps}$ both video and audio traffic transmission and reception.

Table 6. Quality of service for various setting of channel capacity of WAN connection.

\begin{tabular}{|c|c|c|c|c|c|c|c|c|c|}
\hline \multirow[b]{2}{*}{$\begin{array}{l}\text { Traffic } \\
\text { Type }\end{array}$} & \multirow[b]{2}{*}{$\begin{array}{c}\text { QoS } \\
\text { Parameter }\end{array}$} & \multicolumn{2}{|c|}{$128 \mathrm{kbps}$} & \multicolumn{2}{|c|}{$512 \mathrm{kbps}$} & \multicolumn{2}{|c|}{$1 \mathrm{Mbps}$} & \multicolumn{2}{|c|}{$2 \mathrm{Mbps}$} \\
\hline & & $\begin{array}{c}\text { Trans } \\
\text { mit }\end{array}$ & Receive & $\begin{array}{c}\text { Trans } \\
\text { mit }\end{array}$ & Receive & $\begin{array}{c}\text { Trans } \\
\text { mit }\end{array}$ & Receive & $\begin{array}{c}\text { Trans } \\
\text { mit }\end{array}$ & Receive \\
\hline \multirow{3}{*}{ Video } & Throughput & $\begin{array}{l}281 \\
\text { kbps }\end{array}$ & $24 \mathrm{kbps}$ & $\begin{array}{l}155 \\
\text { kbps }\end{array}$ & $\begin{array}{l}317 \\
\text { kbps }\end{array}$ & $\begin{array}{l}279 \\
\text { kbps }\end{array}$ & $\begin{array}{l}313 \\
\text { kbps }\end{array}$ & $\begin{array}{l}321 \\
\text { kbps }\end{array}$ & $\begin{array}{l}346 \\
\text { kbps }\end{array}$ \\
\hline & Packet loss & $0.0 \%$ & $84.3 \%$ & $0.0 \%$ & $0.0 \%$ & $0.0 \%$ & $0.0 \%$ & $0.0 \%$ & $0.0 \%$ \\
\hline & Jitter & $0 \mathrm{~ms}$ & $125 \mathrm{~ms}$ & $0 \mathrm{~ms}$ & $8 \mathrm{~ms}$ & $0.0 \%$ & $3 \mathrm{~ms}$ & $0.0 \%$ & $1 \mathrm{~ms}$ \\
\hline \multirow{3}{*}{ Audio } & Throughput & $\begin{array}{l}64 \\
\mathrm{kbps}\end{array}$ & $26 \mathrm{kbps}$ & $\begin{array}{l}64 \\
\text { kbps }\end{array}$ & $64 \mathrm{kbps}$ & $\begin{array}{l}64 \\
\text { kbps }\end{array}$ & $64 \mathrm{kbps}$ & $\begin{array}{l}64 \\
\mathrm{kbps}\end{array}$ & $64 \mathrm{kbps}$ \\
\hline & Packet loss & $0.0 \%$ & $29.2 \%$ & $0.0 \%$ & $0.0 \%$ & $0.0 \%$ & $0.0 \%$ & $0.0 \%$ & $0.0 \%$ \\
\hline & Jitter & $0 \mathrm{~ms}$ & $21 \mathrm{~ms}$ & $0 \mathrm{~ms}$ & $7 \mathrm{~ms}$ & $0 \mathrm{~ms}$ & $2 \mathrm{~ms}$ & $0 \mathrm{~ms}$ & $1 \mathrm{~ms}$ \\
\hline
\end{tabular}

\subsection{Impact of Trust CoS and Trust DSCP QoS Model}

We measured Trust CoS and Trust DSCP from main campus to sub campus \#2 to show the impact of enabling Trust CoS and Trust DSCP. We enabled Trust $\mathrm{CoS}$ for all interfaces of Layer 2 devices (i.e., switches), whereas teleconferencing data passing-through. Meanwhile, Trust DSCP is configured on all interfaces of Layer 2 devices and Layer 3 devices (i.e., routers). 


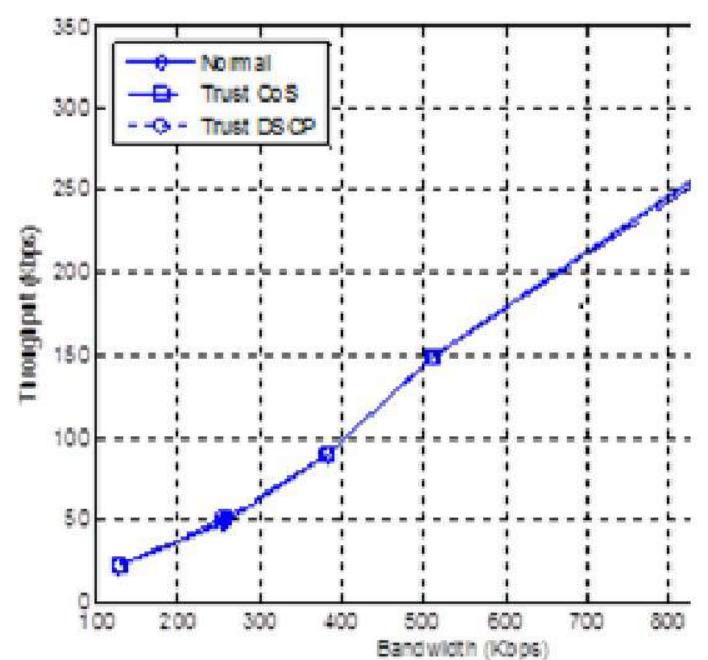

(a)

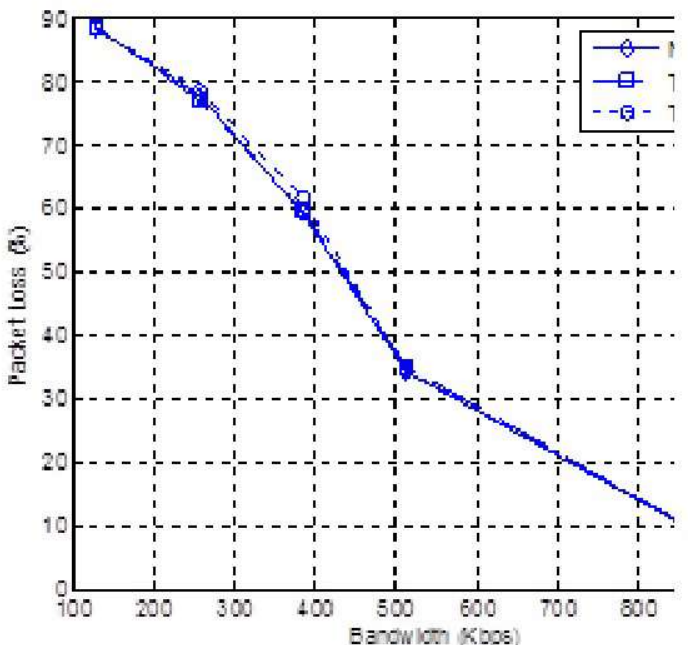

(b)

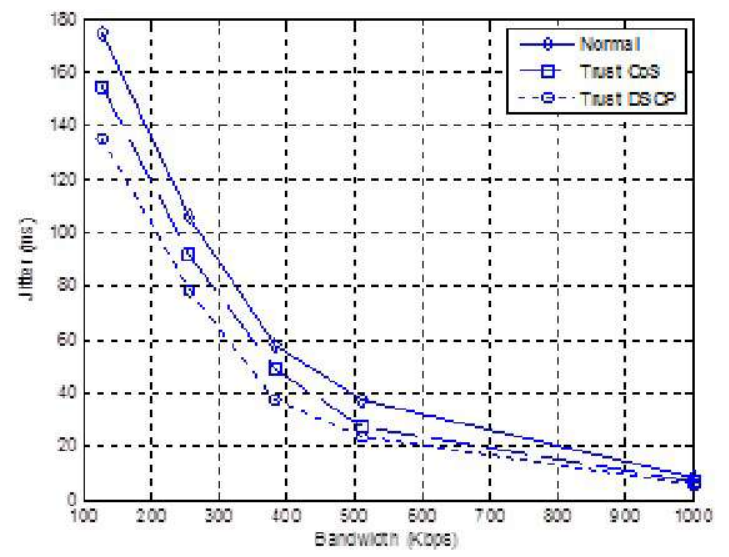

(c)

Figure. 3. Quality of service in our conferencing system comparison in term of (a)

Throughput (b) Packet Loss, and (c) Jitter.

Figure 3 shows the quality of service comparison between 3 measurements, the first measurement is in the normal conferencing system which means no any QoS model inserted. The second and third measurement are inserted Trust CoS and Trust DSCP, respectively. Here, the impact of QoS model both Trust CoS and Trust DSCP is the priority of packet delivery which has critical state on the class-map, so that jitter becomes smaller whereas throughput and packet loss are relatively constant. Jitter decreases from $174.67 \mathrm{~ms}$ to $154.33 \mathrm{~ms}$ and in the second measurement. Meanwhile, it becomes $135 \mathrm{~ms}$ in the third measurement. In this case, jitter decreases $12.33 \%$ when the used of Trust CoS, and $22.41 \%$ when the used of Trust DSCP.

The second scenario, we flooded the path of conferencing traffic data with file transfer packet traffic. Figure 4 shows the impact of this additional traffic data on the conferencing system. Here the role of Trust CoS and Trust 
DSCP is still in decreasing jitter. It is $11.5 \%$ and $20.99 \%$ decreasing when implementing Trust CoS and Trust DSCP, respectively.

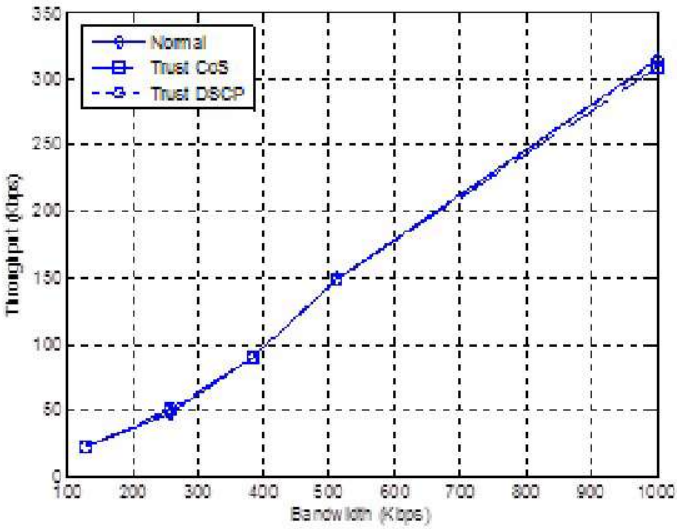

(a)

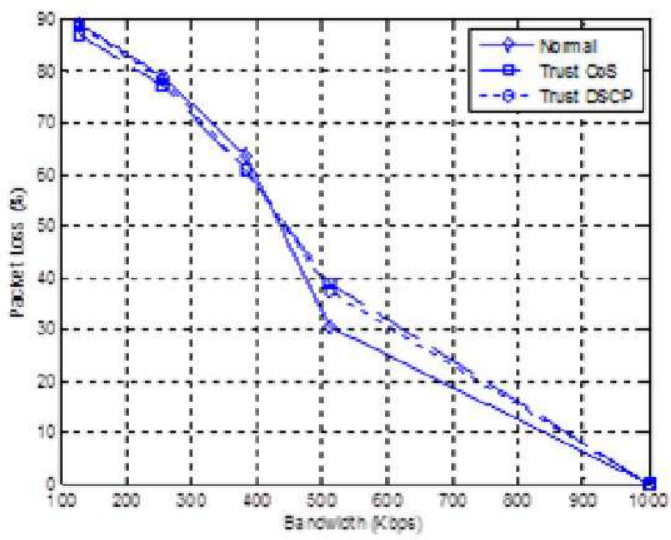

(b)

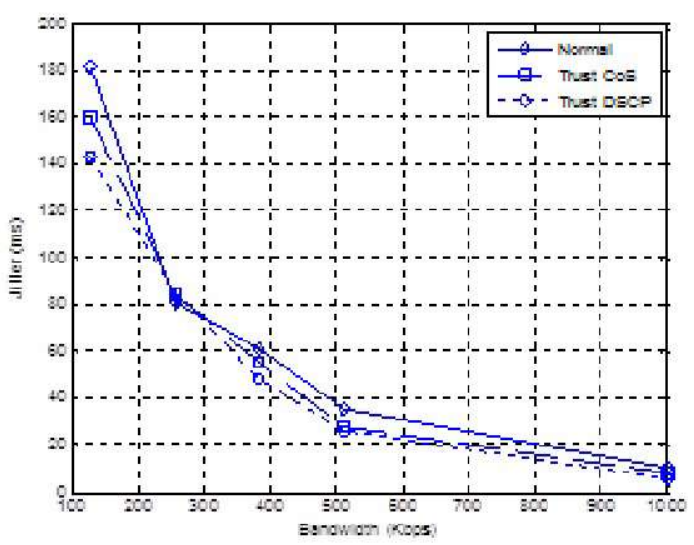

(c)

Figure. 4. Quality of service in our conferencing system comparison with inserting file transfer packet traffic in term of (a) Throughput (b) Packet Loss, and (c) Jitter.

The third scenario, we flooded WAN connection between main campus and sub campus \#2 with UDP traffic data. Here, we utilized UDPFlooder as a tool for flooding UDP data into WAN connection. Figure 5 shows the impact of inserting UDP traffic data to the performance of conferencing system. Again, additional traffic data decreases jitter when packet delivered. The number of packet is varied from 0 to 10,000,000. Meanwhile, throughput and packet loss are relatively constant. 


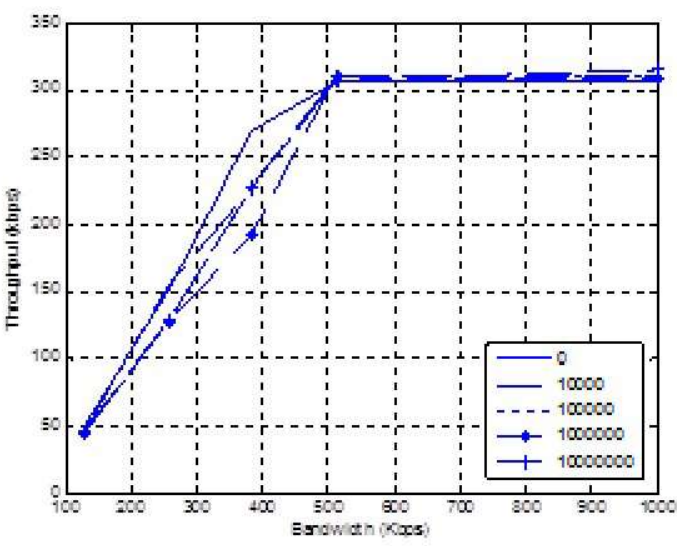

(a)

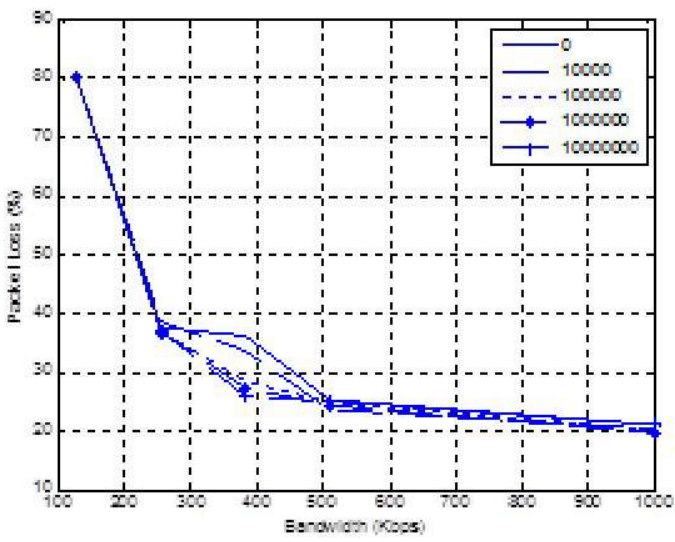

(b)

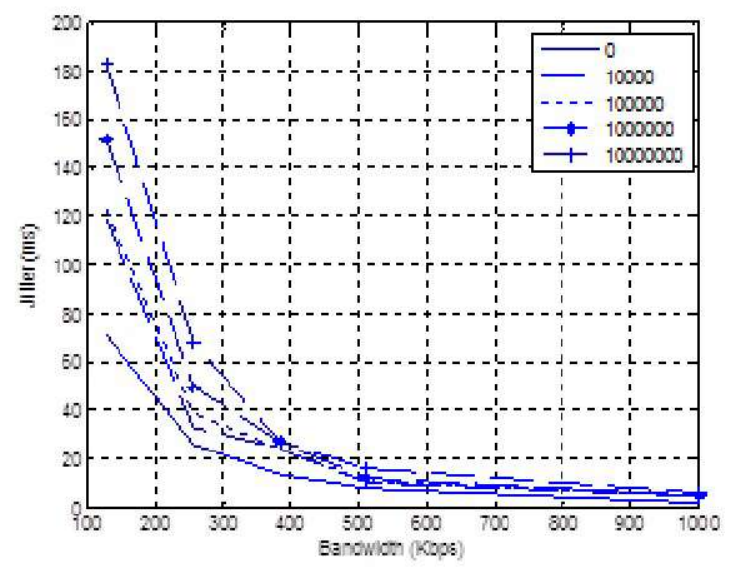

(c)

Figure. 5. Quality of service in our conferencing system comparison with inserting UDP data traffic in term of (a) Throughput (b) Packet Loss, and (c) Jitter.

\section{CONCLUSION AND FUTURE WORKS}

We have presented a testbed of video conferencing system for distance learning between End-point in main campus and End-points in sub campus for laboratory scale. Our experimental results show that the quality of service:

- for channel capacity (bandwidth) of WAN connection 128 kbps produces the throughput of video traffic transmission and reception is $281 \mathrm{kbps}$ and $24 \mathrm{kbps}$, respectively with total packet loss is $84.3 \%$ and jitter is $125 \mathrm{~ms}$, whereas the throughput of audio traffic transmission and reception is 64 kbps and $26 \mathrm{kbps}$, respectively with total packet loss is $29.2 \%$ and jitter is $21 \mathrm{~ms}$;

- for channel capacity of WAN connection 512 kbps produces the throughput of video traffic transmission and reception is $290 \mathrm{kbps}$ and $130 \mathrm{kbps}$, respectively with total packet loss is $35.4 \%$ and jitter is $25 \mathrm{~ms}$, 
whereas the throughput of audio traffic transmission and reception is 64 kbps with no packet loss and jitter is $14 \mathrm{~ms}$;

- for channel capacity of WAN connection $1 \mathrm{Mbps}$ or more (i.e., $2 \mathrm{Mbps}$ ), the throughput of video traffic transmission and reception is $279 \mathrm{kbps}$ and 313 kbps, respectively, whereas the throughput of audio traffic transmission and reception is $64 \mathrm{kbps}$ without packet loss and jitter is not more than $5 \mathrm{~ms}$.

- applying QoS model in the conferencing system decreases jitter. Trust CoS and Trust DSCP model decrease jitter up to $12.3 \%$ and $22.41 \%$, respectively.

Our future works include the application of QoS for all nework devices in access, distribution, and core levels where video/audio traffic passthrough. In addition, we also would like to optimize the quality of service by collaborating non-QoS parameters and QoS application to achieve better performance of video conferencing, and implement video conferencing system for real distance learning.

\section{REFERENCES}

[1] Agosti G (2006). Distance education in the era of Internet. Encyclopedia of developing regional communities with information and communication technology. Idea Group Reference.

[2] Nugraha A.A, Yonathan B, Bandung Y, dan Langi A.Z.R (2010). Tantangan dalam implementasi layanan digital learning pedesaan: studi kasus jaringan testbed Keerom-Papua. Proceeding of konferensi dan temu nasional teknologi informasi dan komunikasi (TIK) untuk Indonesia 2010, Bandung.

[3] Yonathan B, Bandung Y, dan Langi A.Z.R (2011). Analisis kualitas layanan (QoS) audio-video layanan kelas virtual di jaringan digital learning pedesaan. Proceeding of Konferensi Teknologi Informasi dan Komunikasi untuk Indonesia 14-15 Juni 2011, Bandung.

[4] Yonathan B, Nugraha A.A, Bandung Y, dan Langi A.Z.R (2010). Layanan kelas virtual dengan multimedia streaming untuk mendukung digital learning pedesaan: studi kasus Keerom-Papua. Proceeding of konferensi dan temu nasional teknologi informasi dan komunikasi (TIK) untuk Indonesia 2010, Bandung.

[5] Sudiarjo S (2010). Pengukuran parameter kualitas layanan (QoS) trafik video streaming pada jaringan IP berbasis switch layer 2. Fakultas Teknik, Prodi Teknik Elektro, Universitas Indonesia.

[6] Yuksel M, Ramakrishman K.K, Kalyanaraman S, Houle J.D, and Sadhavi, R. (2007). Value of Supporting Class-of-Service in IP Backbones. IEEE International Workshop on Quality of Service. Evanston, H, USA, pp. 109-112. 
[7] Revathi P. and Balasubramanian R. (2009). Efficiency analysis on QoS multicast routing protocols under cross-layer approach with bandwidth estimated admission control. International journal of algorithms, computing and mathematics, vol. 2, no. 3, August.

[8] Cisco, Cisco Unified Communications (2010). New Deployment Models for Communications and Collaboration. Cisco White Paper, Cisco and/or its affiliates.

[9] Cisco (2009). Cisco Unified Videoconferencing Solution Reference Network Design (SRND). Cisco White Paper, Cisco and/or its affiliates, 2009.

[10] Smith C.D (2003). Quality of service configuration for TCP/IP video conferencing. PlanNet Consulting, September 2003.

[11] Cisco (2012). Enterprise QoS solution reference network design guide. Medianet Campus QoS Design ver. 4.0. 